\title{
Optimization Calculation and Ergonomics Evaluation of Civil Aircraft Passenger Cabin Layout
}

\author{
Yuhui Sheng ${ }^{1}$, Xiaoru Wanyan ${ }^{1,}$ a, ${ }^{,}$, Damin Zhuang ${ }^{1}$, Yue Zhou ${ }^{2}$ \\ ${ }^{1}$ School of Aeronauic Science and Engineering, Beihang University, Beijing, China \\ ${ }^{2}$ Aviation Key Laboratory of Science and Technology on Aero Electromechanical System Integration \\ aZy1505303@buaa.edu.cn
}

Keywords: Cabin layout, optimization calculation, ergonomics evaluation, genetic algorithm, simulation analysis.

\begin{abstract}
Passenger cabin is considered as one of the most important areas in the civil aircraft, and the cabin layout patterns significantly influence the passengers' comfort, airways' profits and the brand images of companies. This research is geared to the needs of dual-channel large aircraft cabin layout and their ergonomics design. In our study, the overall cabin optimization calculation based on genetic algorithm and the individual passenger's comfort evaluation based on the JACK software's simulation analysis are comprehensively adopted, so as to conduct the optimization design for cabin layout and the assessment for the man-machine characteristics of the optimized cabin layout. It can provide the theoretical basis and technical methods for evaluating the comprehensive performance of cabin design of large aircrafts with dual channels.
\end{abstract}

\section{Introduction}

It is generally considered that the passenger cabin is one of the most important areas in the civil aircraft, which plays the role of accommodating and serving passengers during the flight. The cabin layout patterns can significantly influence the passengers' comfort, airways' profits and their brand images of companies. With the development of economy, more and more passengers start to pay close attention to the comfort quality in flight. According to carrying out the researches of passenger cabin layout, the cabin space usage will become more efficient, such as improving the space openness, reducing the sense of oppression and increasing the passengers' moving efficiency. Furthermore, the travel experience will be more comfortable. In the meanwhile, favorable layout will increase the flight safety and airways' profits. These advantages will effectively promote our large aircrafts' competitive power in the market to furtherance Chinese civil aviation.

As a result of previous researchers' efforts, the methods of the optimization calculation and ergonomics evaluation of cabin layout are abundant and valuable [1]. However, the current cabin layout researches mainly focus on the plant [2], steamship [3] and cockpit rather than large aircraft cabin. As dual-channel large aircrafts are mainly utilized for long-time and long-distance flight, passenger's facing obviously have higher standard of comfort requirement and pay much more attention to more contents. Therefore, it's necessary to carry out the researches towards the use requirements and specific environment of large aircraft. Mostly of the previous studies perform researches about cabin layout only using simulation analysis methods [4], lacking of the guide of data index, or only using mathematics method for the optimization calculation without the ergonomics evaluation. Facing the needs of dual channel large aircrafts cabin layout and their ergonomics design, the overall cabin optimization calculation based on genetic algorithm and the individual passenger's comfort evaluation based on the JACK software's simulation analysis are comprehensively adopted, so as to conduct the optimization design for cabin layout and the assessment for the man-machine characteristics of the optimized cabin layout [5]. It can provide the theoretical basis and technical methods for evaluating the comprehensive performance of cabin design of large aircrafts with dual channels. 


\section{Mathematical Modeling and Optimization Calculation of Passenger Cabin Layout}

\subsection{Demand Analysis of Passenger Cabin Layout}

The multifaceted groups' value appeals should be comprehensively considered for the needs of dual channels wide-body aircrafts layout. For example, passengers always expect more legroom in order to have excellent travel experiences when the ticket price is constant, while the airlines prefer to arrange more seats within the limited cabin room so as to get more economic benefits, and the Civil Aviation Administration requires that the cabin layout should accord with the airworthiness requirements such as emergency escape. Therefore, economical efficiency, travel comfort and safety are the key factors which are chosen to be considered in our research.

\subsection{Mathematical Modeling of Passenger Cabin Layout}

\subsubsection{Drawing up the Constraint Conditions}

The target function can get its extremum in the definition domain, and the definition domain is the constraint condition which can be built from the space data of the cabin and seats, including the space between the front and rear seats, the aisle width and the layout pattern of seats. The concrete data can be obtained from the CCAR25-R4 Air worthiness standard of transport aircraft [6], empirical data from airlines and the ergonomics simulation. Taking the Boeing 777 as example, the software CATIA is used to build the materialization cabin model, as shown in Fig 1.

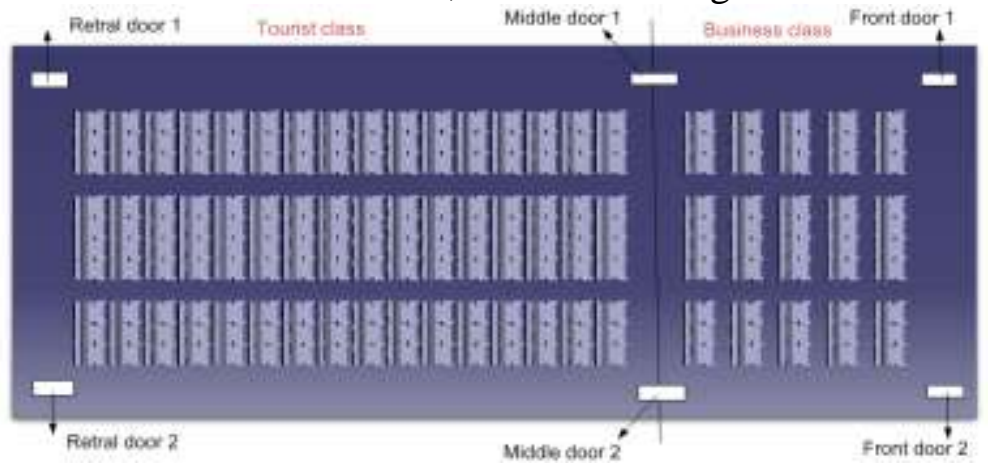

Fig. 1 Cabin layout model

In the Fig 1, the passenger cabin consists of business class and tourist class, which are both equipped with 3-4-3 seat layout. The business class has bigger legroom with higher comfort while the tourist class has smaller legroom with higher economic efficiency. The cabin's length is $20 \mathrm{~m}$, the distance between business class and tourist class is $2 \mathrm{~m}$, and the cabin width is $5.86 \mathrm{~m}$. Based on the rules of 25.815 clause from CCAR25-R4 Air worthiness standard of transport aircraft, if the height of cabin's seat is less than $635 \mathrm{~mm}$ and the number of seats is more than 20 , the aisle width must be more than $0.510 \mathrm{~m}$. Given that seat width of Boeing 777 is about $0.48 \mathrm{~m}$ and per row has ten seats, so the aisle width is $0.530 \mathrm{~m}$, which meets the requirement.

In order to make optimization calculation, the business class row spacing can be set as $x$, the business class row number can be set as $p$, the tourist class row spacing is regarded as $y$, and the tourist class row number is regarded as $q$. taking the value of distance between business class and tourist class as $2 \mathrm{~m}$, then

$$
20=p \mathrm{x}+q \mathrm{y}+2(p \geq 1, q \geq 1)
$$

To get the proper row spacing of business class and tourist class, the typical wide-body aircrafts operated successfully (including A340-300, A330-300, A330-200, B777-300ER and B777-200) are taken as reference in this study. The A330-300 has the biggest tourist class legroom $(0.9398 \mathrm{~m})$, and the A340-300 has the lowest tourist class legroom $(0.7874 \mathrm{~m})$. Therefore, Y can be set between0. $7874 \mathrm{~m}$ and $0.9398 \mathrm{~m}$. By the same way, $\mathrm{X}$ can be set between $1.0668 \mathrm{~m}$ and $1.524 \mathrm{~m}$.

\subsubsection{Establishment of Target Functions}

The target functions are relative to the cabin economy, safety and comfort. The comfort index is indicated by the total passenger legroom, as shown in equation (2), the economy efficiency is indicated by the profit of business cabin ticket price ( $¥ 27500$ ) and tourist cabin ticket price ( $¥ 8000$ ), as shown in equation (3), and the safety is represented by the total escape distance between each passenger and the corresponding emergency exit, as shown in equation (4). 


$$
\begin{aligned}
& F_{1}(x, y)=\left\{\max \left(\sum \sum D\left(X_{i j}\right)\right) \mid D\left(X_{i j}\right)=\left(x_{i}-x_{j}\right)^{2}+\left(y_{i}-y_{j}\right)^{2}, i j \in[1, n], i \neq j\right\} \\
& F_{2}(x, y)=\left\{\max \sum_{1}^{n} M_{i}\right\} \\
& F_{3}(x, y)=\left\{\min \left(\sum \sum D\left(X_{i}\right)\right) \mid D\left(X_{i}\right)=\left(x_{i}-x_{a}\right)^{2}+\left(y_{i}-y_{a}\right)^{2}, i \in[1, n]\right\}
\end{aligned}
$$

In summary, the integrated target function about the mathematical modeling can be built as equation (5).

$$
F(x, y)=U \mu_{i} F_{i}(x, y), i=1,2,3(p \geq 1, q \geq 1,1.0688 \ll x \ll 1.5240 .7874 \ll y \ll 0.9398)
$$

\subsection{Solving the Maximum of Target Function}

The function maximum can be obtained through the improved genetic algorithm in the MATLA $\mathrm{B}$,where all the parameter of the mathematical modeling is input and its constraint condition is rewrite as matrix. When the function value becomes convergence, the maximum is 2654500 , as well as the $\mathrm{p}=5, \mathrm{q}=16, \mathrm{x}=1.0801$ and $\mathrm{y}=0.7874$. According to the optimization calculation, the target function has the maximum in the constraint condition. When the number of business class seat rows is set as 5, the distance between the front and later row is set as $1.08 \mathrm{~m}$, the number of tourist class seat rows is set as 16 , and the distance between the front and later row is set as $0.7874 \mathrm{~m}$, the layout can be improved to be the optimization.

\section{Ergonomics Evaluation of Passenger Cabin Based on Virtual Simulation}

After the optimum solution of the overall layout scheme is gotten by genetic algorithm, we use the virtual simulation based on JACK for the evaluation and analysis of cabin ergonomics[7]. According to various simulation analysis modules, JACK can provide the visualization results of human modeling and attitude simulation, which helps the designers to quickly understand the man-machine combination situations. The JACK modules include vision field analysis, reaching zones analysis, comfort zone analysis, lower back analysis, action energy, metabolic energy, expenditure, RULA(Rapid Upper Limb Assessment), NIOSH(National Institute for Occupational Safety and Health), OWAS(Ovako Working Posture Analysis System), Image of virtual simulation and limb accessibility, resulting in the high evaluation efficiency during the early design stage.

\subsection{Building of Occupant Model}

Based on the GB/T10000-88 Chinese Adult Body Size data[8], the 5th, 50th and 95th percentile human models of male and female are built, respectively (see Fig. 2), and the following simulation analysis is carried out on the basis of the built human models.

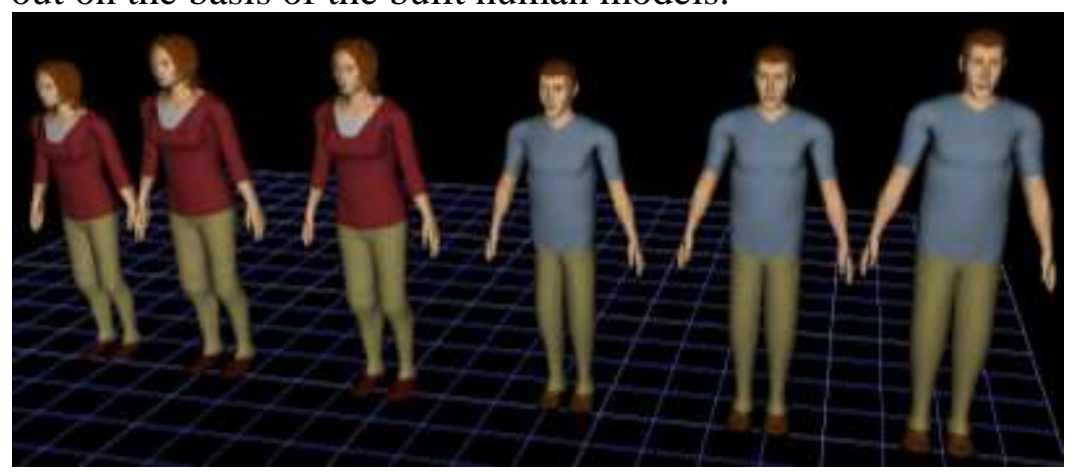

Fig. 2 Occupant model with different percentiles

\subsection{Simulation Analysis Methods Chosen Based on Typical Postures}

In order to conduct the virtual simulation and ergonomics evaluation of the optimized cabin layout, the basic postures in the passenger cabin are analyzed, including sitting, standing and walking. Furthermore, the typical activities based on the three kind of basic postures are taken into account. The concrete postures include four kinds of sitting postures, two kinds of standing postures and two kinds of walking postures. Besides, the corresponding simulation analysis modules of JACK are chosen for different scenes, as shown Table 1[9]. 
Table 1. Simulation analysis methods chosen based on typical postures

\begin{tabular}{|c|c|c|}
\hline $\begin{array}{c}\text { Basic } \\
\text { postures }\end{array}$ & Typical activities(scenes) & Simulation analysis modules of JACK \\
\hline \multirow{4}{*}{$\begin{array}{l}\text { Sitting } \\
\text { postures }\end{array}$} & Taking off; landing & OWAS; Lower Back Analysis \\
\hline & $\begin{array}{l}\text { Watching entertainment } \\
\text { system }\end{array}$ & Vision fields \\
\hline & Breaking; sleeping & OWAS; Lower Back Analysis \\
\hline & $\begin{array}{l}\text { Eating; reading; using } \\
\text { computers }\end{array}$ & Reaching zones \\
\hline \multirow{2}{*}{$\begin{array}{l}\text { Standing } \\
\text { postures }\end{array}$} & Taking out luggages & \multirow{2}{*}{$\begin{array}{c}\text { Lower Back Analysis; Metabolic Energy; } \\
\text { Expenditure; RULA; NIOSH; Reaching zones }\end{array}$} \\
\hline & Deposit luggages & \\
\hline \multirow{2}{*}{$\begin{array}{l}\text { Walking } \\
\text { postures }\end{array}$} & $\begin{array}{c}\text { Passengers across passing } \\
\text { the aisle }\end{array}$ & \multirow{2}{*}{ Image of virtual simulation } \\
\hline & $\begin{array}{l}\text { Passing from the inside seat } \\
\text { to the aisle }\end{array}$ & \\
\hline
\end{tabular}

\subsection{Ergonomics Evaluation of Passenger Cabin Layout}

Given that the comfort quality of business class is higher than tourist class, this study primarily focuses on the passenger comfort and layout rationality for the tourist class.

For the sitting postures, taking the scene of 'watching the entertainment system' as example, the 50th percentile male and females passengers are chosen as the evaluation objects, and the occupant models are adjusted to the corresponding sitting postures in the tourist class. Fig. 3 shows the binocular visions of man and female passengers, respectively. The results indicate that the entertainment systems are in the range of passengers' great visions, and thus the passengers can use the entertainment system comfortably.
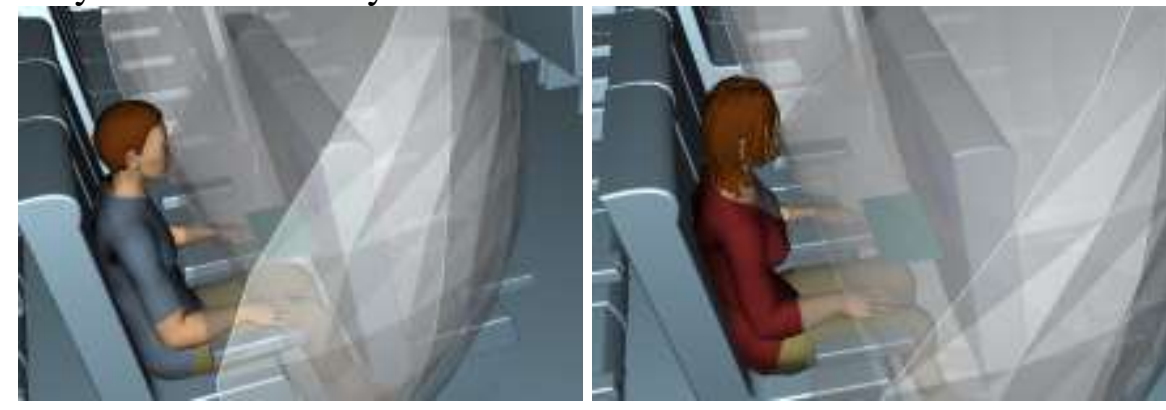

Fig. 3 Simulation results of vision fields for male and female passengers

The 5th percentile adult male is chosen as the evaluation objects and the postures are adjusted to lifting up the luggages. The corresponding parameters are set and we get the result. Fig. 4 shows the energy in the depositng luggages is $0.237 \mathrm{kcal}$, the standing energy is $0.169 \mathrm{kcal}$ and the action insists for 12 seconds, so the rate of energy to time is $2.032 \mathrm{kcal} / \mathrm{min}$. The number is lower than the limitation $7.372 \mathrm{kcal} / \mathrm{min}$ given by the NOISH[10].

For the walking postures, taking the scene of 'passengers across passing the aisle' as example, the 50th percentile male and females passengers are chosen as the evaluation objects, and the occupant models are adjusted to the corresponding walking postures in the tourist class. The virtual simulation of JACK presents the relative positions of two passengers passing across the aisle, which shows this aisle width meets the lowest requirement and has a better economy, as shown in Fig. 5. 


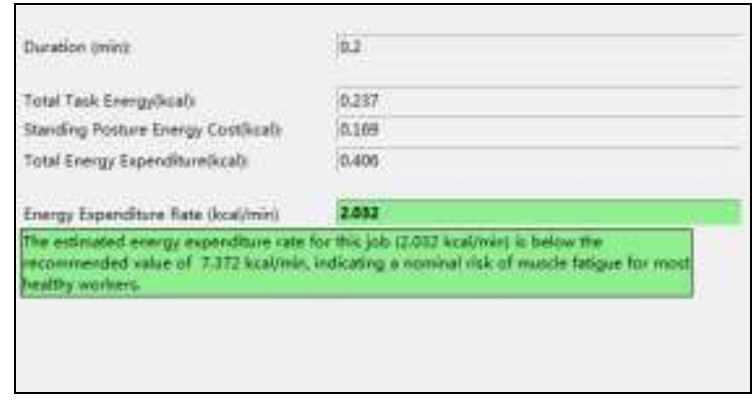

Fig. 4 The energy rate when passengers lift luggages

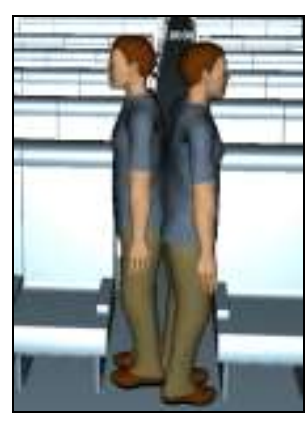

Fig. 5 Passengers passing across the aisle

The evaluation results of other postures can also be obtained by the similar simulation methods. The results indicated that all the postures presented in Table 1 are comfortable, reasonable and safe. Therefore, the optimized layout design achieves the desired effect.

\section{Conclusion}

The current study is focused on the layout optimization design of domestic dual-channel large aircraft cabin. Mathematic model is created on the usage requirements analysis, and the genetic algorithm is adopted to get the quantitative optimum solution, which is proved to be a useful and efficient method for the improvement of traditional layout design. Furthermore, to validate whether the layout meets the ergonomics requirement, different percentile occupant models of male and female are built by JACK software, and the passengers' basic postures and typical activities are decomposed in detail. The corresponding simulation analysis modules of JACK are chosen for evaluating different postures, and the final results show that the optimized design achieves the desired effect of economy, safety and comfort. According to comprehensive application of optimization calculation and simulation evaluation, the layout design can be improved effectively.

\section{References}

[1]. Changhui Song. The Usage of Improved Genetic Algorithm in the Equipment Layout [D]. Nanjing: Nanjing University of Science \& Technology, 2009.

[2]. Na Zhou, Kelin Xu, Shuang Guo. The Multiobjective Optimization of the Plant Based on Genetic Algorithm [J]. Industrial Engineering. Vol. 14(2011) No. 5, p. 104-109.

[3]. Yao Hu, Yefang Jiang, Zhiguo Xiong, Jian Wang. The Optimization of the Ship Based on Improved Genetic Algorithm [J]. Chinese Journal of Ship Research. Vol. 9(2013) No. 1, p. 19-26.

[4]. Xiaoli Luo, Hailong Li. The Operating Load Evaluation of Air Crew Based on JACK [J]. Journal of Safety Science and Technology. Vol. 11(2015) No. 4, p. 192-196.

[5]. Duming Liu, Xiaoping Wang, Dengkai Chen, Shuxia Wang. The Cockpit Simulation and Ergonomics Analysis [J]. Jisuanji Yu Xiandaihua. Vol. 8(2013), p. 106-110.

[6]. CAAC. CCAR25-R4.2011.

[7]. Jianwei Niu. Human Factors Engineering Basis and Examples of JACK[M]. Electronics Industry Press, 2012.

[8]. State Bureau of Technical Supervision. GB10000-88 Human Dimensions of Chinese Adults [M]. 1988.

[9]. Zhi Ma, HongJun Xue, Rune Su. Human Modelling Building and Ergonomics Analysis of JACK [J]. Aeronautical Computing Technique. Vol. 38(2008), p. 97-100.

[10]. Emilie Poirson and Mathieu Delangle. Comparative Analysis of Human Modeling Tools. 2nd International Digital Human Modeling Symposium (DHM). 2013: 1-6. 